\title{
Knowledge and perception of microbicides among healthcare providers in Calabar, Nigeria
}

\author{
Aniekan J. Etokidem ${ }^{1}$, Daprim S. Ogaji ${ }^{2}$, Ita B. Okokon ${ }^{3}$
}

1. Department of Community Medicine University of Calabar, Calabar, Nigeria.

2. Department of Preventive and Social MedicineUniversity of Port Harcourt, Rivers State, Nigeria.

3. Department of Family MedicineUniversity of Calabar, Calabar, Nigeria.

\begin{abstract}
Background: With the worldwide spread of HIV/AIDS, the absence of a known cure and the challenges associated with existing prevention methodologies, there is need for new prevention technologies. The successful uptake of healthcare products and services depend, to a large extent, on healthcare providers' knowledge, perception and attitude regarding them.

Objectives: To determine the knowledge and perception of healthcare providers regarding microbicides.

Methods: A semi-structured questionnaire was administered on 400 randomly selected health care providers in Calabar, Cross River State of Nigeria. Data obtained from the 350 returned questionnaire were analyzed using EPI -Info software version 3.5.1

Results: One hundred and sixty-four (46.9\%) respondents were medical doctors while $157(44.9 \%)$ were nurses, $7(2 \%)$ were Pharmacists and $22(6.2 \%)$ belonged to "other" categories. Thirty- two percent knew the advantages of microbicides over condoms. Sixty-eight percent indicated that microbicides would benefit only women while to $27 \%$, it would benefit both men and women. Seventy-five percent of respondents would be willing to act as community advocates for microbicides while $21 \%$ would not be willing and $4 \%$ were not decided. There was a statistically significant association between professional group and willingness to act as community advocates for microbicides. Medical doctors were more likely to act as advocates than other professional groups $(\mathrm{p}<0.05)$. Female respondents were more likely to have correct knowledge regarding microbicides than males $(\mathrm{p}<0.05)$
\end{abstract}

Conclusion: There are gaps in knowledge regarding microbicides among the health care providers. Capacity building would be successful since the majority are willing to act as community advocates.

African Health Sciences 2014; 14(2):281-287

DOI: http://dx.doi.org/10.4314/ahs.v14i2.2

\section{Background}

The first diagnosis of HIV was reported in the United States of America by the Centers for Disease Control among gays on June $5,1981^{1}$. Since then, the infection has spread to all parts of the world and has eventually become a pandemic. By the end of 2007, UNAIDS reported that $46 \%$ (15.4 million) of people living with HIV/AIDS worldwide were women ${ }^{2}$.

\section{Corresponding author: \\ Dr. Aniekan J. Etokidem MBBCh \\ Department of Community Medicine \\ University of Calabar Teaching Hospital \\ Calabar, Nigeria. \\ Email: anietokidem@yahoo.com \\ Phone: $+234(0) 8038227878$}

In sub-Saharan Africa, almost 60 per cent of adults living with HIV/AIDS in 2007 were women ${ }^{3}$. Every day, nearly 7,500 people become infected with HIV and 5,500 die from AIDS, mostly due to lack of HIV prevention and treatment services ${ }^{2}$.

In Nigeria, the first officially reported diagnosis of HIV was made in a 13-year old female hawker from Benue state in 1986. Since then, HIV prevalence in the country has increased from $1.8 \%$ in 1991 to $3.8 \%$ in 1993, 4.5\% in $1995,5.4 \%$ in 1999 and $5.8 \%$ in $2001^{4}$. Although the prevalence declined to $5.0 \%$ in $2003,4.4 \%$ in 2005 , 4.6\% in 2008 and 4.1\% in 2010, Nigeria currently has the third highest number of People Living with HIV / AIDS in the world, after South Africa and India ${ }^{4,5,6}$.

Aware that prevention is better and cheaper than cure, mankind has tried several prevention options since the onset of the pandemic namely, abstinence, condom use, being faithful to one uninfected, faithful partner, 
amongst others. Most of these prevention options are not feasible for millions of people around the world, especially women, who are the most infected and worst affected by the HIV/AIDS pandemic. It has been demonstrated that women do not have the social and or economic power necessary to insist on condom use and fidelity or to abandon partnerships that put them at risk $^{7}$. All these problems led to the search for an HIV prevention method that would be under the control of women, which have been named New Prevention Technologies (NPTs). Two of such technologies, HIV vaccines and microbicides, are currently undergoing trials and will very likely be available for widespread use in the next few years. None of these new methods require a partner's cooperation. They would put the power to protect into women's hands ${ }^{8,9}$.

The term microbicides refers to a new type of product being developed that people could use vaginally or rectally to protect themselves from HIV and possibly other sexually transmitted infections. A microbicide could be produced in many forms, including gels, creams, suppositories, films, sponge or ring that releases the active ingredient over time. Microbicides would be the most important innovation in reproductive health since the advent of the pill'.

A study in South Africa demonstrated the need for research and awareness creation about microbicides among health care providers prior to making the product available. This is because health care providers have a critical role in informing clients about these new HIV prevention measures ${ }^{10}$.

\section{Introduction}

The worst affected of the over 30 million people living with HIV /AIDS worldwide are women ${ }^{2,3}$. With the absence of any known cure, the failure of current preventive measures and an epileptic anti-retroviral drug supply, especially in developing countries where they are mostly needed, there is need for newer prevention strategies. Such strategies should be more affordable and within the control of the most affected segment of the population ${ }^{9,10}$. Microbicides, a new class of product meant for topical use, have the potential of meeting this need $^{11}$.

Although there are presently no microbicides available for widespread use, most of the candidate microbicides being at various stages of trial, there is need for research and awareness creation about this preventive measure. This is because historically, there is always a time lapse between when new drugs and health technologies have are designed and developed for industrialized markets and when they are introduced into developing countries, usually several years later, if at all ${ }^{9}$. There is therefore need to start the groundwork now to ensure that microbicides, once developed, can quickly become available to women in developing countries ${ }^{7,9}$.

To ensure such access and prepare for the introduction of such technologies, there is need to determine how much health care providers know about these technologies with a view to filling any identified knowledge gap through capacity building and advocacy.

Such research and awareness is also necessary among health care providers because not only are they the primary source of reproductive health information for potential users both in the public and private health institutions, their perception of microbicides will also influence their clients' perception regarding this preventive method. More so, health care providers could play a critical role in the success of microbicide research and trials, by providing manpower and technical direction.

Although some studies on the knowledge of health care providers regarding microbicides have been conducted in other countries ${ }^{10,11,12}$, there is a dearth of such studies in Nigeria. This study therefore seeks to contribute towards filling this gap.

\section{General objective of the study}

The general objective of this study was to determine the knowledge and perception of health care providers regarding microbicides.

\section{Specific objectives}

The specific objectives of this study were:

To determine the knowledge of health care providers in Calabar regarding microbicides

To determine the perception of health care providers in Calabar regarding microbicides

\section{Materials and methods}

A semi-structured self- administered questionnaire was administered on 400 randomly selected health care providers in Calabar, Cross River State of Nigeria. A list of private health care facilities and another list of public health care facilities were compiled. Two public hospitals (one secondary and one tertiary) and six private clinics were randomly selected. In the facilities, using the duty roster, systematic random sampling was used to select health care providers to participate in the study. Data collection was done by 5 trained data collectors in 2011. The questionnaire sought information regarding their socio-demographic characteristics, knowledge and perception regarding microbicides, willingness to act as 
community advocates. Three hundred and fifty (350) questionnaire were returned. Data obtained from the respondents were analysed using EPI -Info software version 3.5.1. Results were presented as tables. Ethical approval for the study was obtained from the Research Ethics Committee of the University of Calabar Teaching Hospital, Calabar.

\section{Results}

Majority of the respondents, $156(44.6 \%)$ were aged between 30-39 while only 9 (2.6\%) belonged to the 60 and above age group. Two hundred (57.1\%) respondents were females while $150(42.9 \%)$ were males. Majority of the respondents, $270(77.1 \%)$ were employed in the public sector while $77(22 \%)$ were employed in the private sector. One hundred and sixty-four $(46.9 \%)$ were medical doctors while 157 (44.9\%) were nurses, $7(2 \%)$ were pharmacists and 22(6.2\%) belonged to the "other" category (Table 1).

Table 1: socio-demographic variables

\begin{tabular}{|l|l|l|}
\hline Variable & Frequency & Percent \\
\hline Age group & & \\
\hline $20-29$ & 70 & $20 \%$ \\
\hline $30-39$ & 156 & $44.6 \%$ \\
\hline $40-49$ & 55 & $15.7 \%$ \\
\hline $50-59$ & 60 & $17.1 \%$ \\
\hline 60 and above & 9 & $2.6 \%$ \\
\hline Total & 350 & $100 \%$ \\
\hline Sex & & \\
\hline Male & 150 & $42.9 \%$ \\
\hline Female & 200 & $57.1 \%$ \\
\hline Total & 350 & $100 \%$ \\
\hline Marital status & & \\
\hline Never married & 43 & $12.3 \%$ \\
\hline Married & 257 & $73.4 \%$ \\
\hline Separated & 21 & $6 \%$ \\
\hline Divorced & 15 & $4.3 \%$ \\
\hline Widow & 14 & $4 \%$ \\
\hline Total & 350 & $100 \%$ \\
\hline Type of health facility & & \\
\hline Private & 77 & $22 \%$ \\
\hline Public & 270 & $77.1 \%$ \\
\hline Non-response & 3 & $0.9 \%$ \\
\hline Total & 350 & $100 \%$ \\
\hline Professional group & & \\
\hline Medical doctor & 164 & $46.9 \%$ \\
\hline Nurse & 157 & $44.9 \%$ \\
\hline Pharmacist & 7 & $2 \%$ \\
\hline Other & 22 & $6.2 \%$ \\
\hline Total & 350 & $100 \%$ \\
\hline
\end{tabular}

Radio was the main source of information regarding microbicides (30.7\%) followed by Newspapers (28.5\%) while very few respondents, 23(5.0\%) obtained information from friends and $35.8 \%$ obtained information from other sources (Table 2).

One hundred respondents $(28.6 \%)$ correctly defined new HIV prevention strategies while majority, 185 $(52.9 \%)$ indicated that the female condom is an example of new prevention technology. Three hundred $(33.9 \%)$ of the responses given indicated that new prevention technologies are drugs taken orally after sexual intercourse with an HIV infected partner or a partner whose sero-status is unknown to prevent the transmission of HIV while $100(11.3 \%)$ of the responses indicated that microbicides were NPTs and a similar proportion (11.3\%) also indicated that HIV vaccines are NPTs(Table 3$)$.

Only $8.1 \%$ of the respondentsindicated that microbicides are a new group of substances that can reduce the risk of HIV and other STIs when applied topically before 
Table 2: source of information about microbicides

\begin{tabular}{|l|l|l|}
\hline Source of information & Frequency & Percent \\
\hline Radio providers/ & 140 & $30.7 \%$ \\
\hline Television & 50 & $11 \%$ \\
\hline $\begin{array}{l}\text { Health care } \\
\text { colleagues }\end{array}$ & 41 & $9.0 \%$ \\
\hline Newspapers & 130 & $28.5 \%$ \\
\hline Medical journals & 72 & $15.8 \%$ \\
\hline Friends & 23 & $5.0 \%$ \\
\hline TOTAL & $456^{*}$ & $100 \%$ \\
\hline
\end{tabular}

*Multiple responses allowed.

sexual intercourse while majority, $42.7 \%$ indicated that microbicides are microorganisms that can destroy HIV. Concerning the formulation of microbicides, $42.3 \%$ indicated that microbicides could be in the form of oral tablets(Table 3).

Two hundred and nine (59.7\%) respondents indicated that it would not be safe to use microbicides alongside other prevention methods like condoms while only $107(30.6 \%)$ indicated that it would be safe to do so and $9.7 \%$ indicated that they did not know.

Sixty-eight percent of respondents indicated that microbicides would be of benefit to only women, because it is a woman-controlled method while $95(27 \%)$ indicated that it would benefit both men and women. Only $36(10.3 \%)$ respondents indicated that microbicides would be useful in prevention of Mother to Child Transmission of HIV while 235 (67.1\%) indicated that it would not be useful.

Two hundred and sixty-two (75\%) respondents indicated that they would be willing to act as community advocates for the microbicides campaign while only 74 (21\%) indicated that they would not and $4 \%$ were undecided.

Table 3: knowledge and perception regarding microbicides

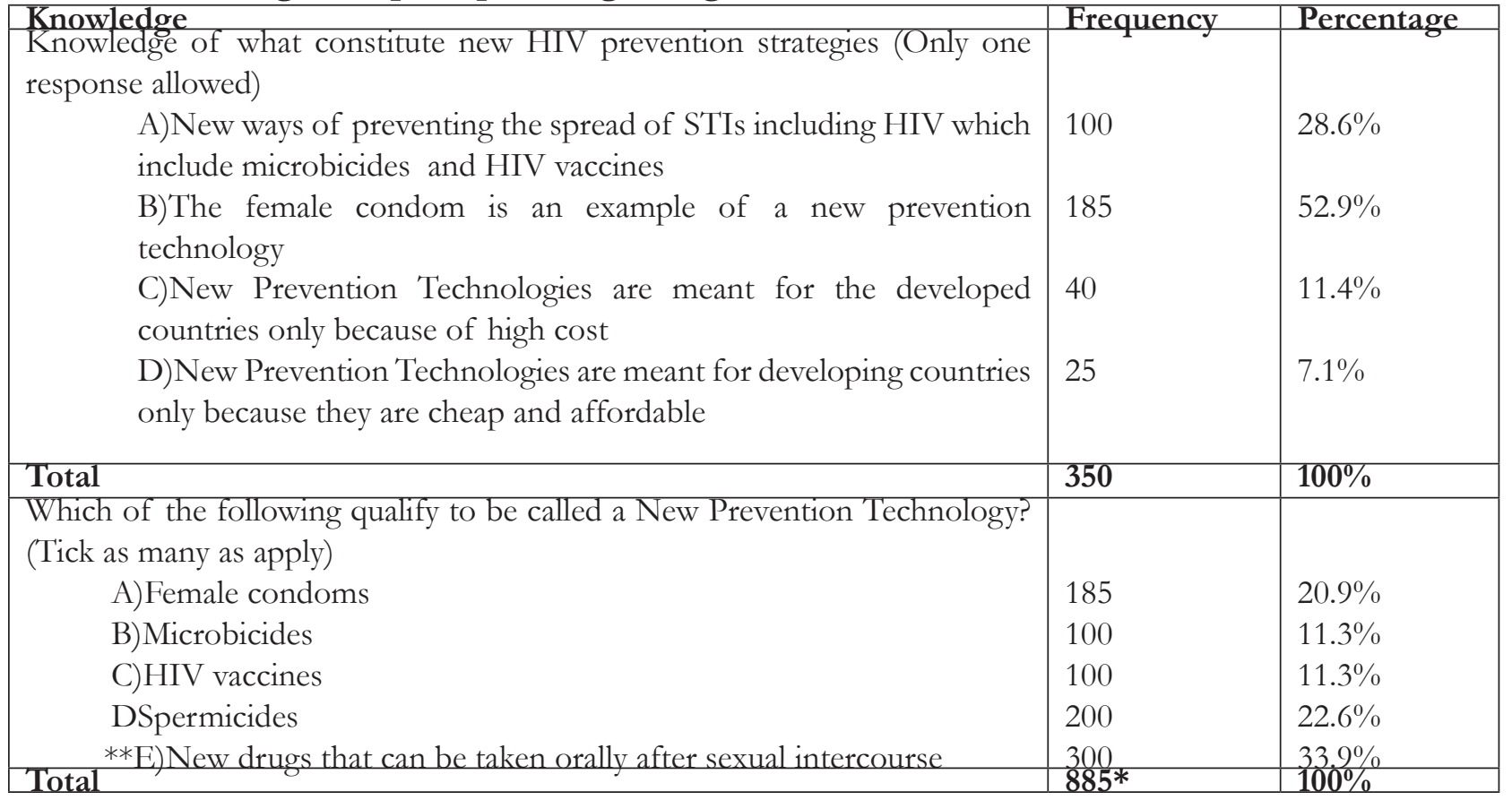

**with an HIV infected partner or a partner whose sero-status is unknown 


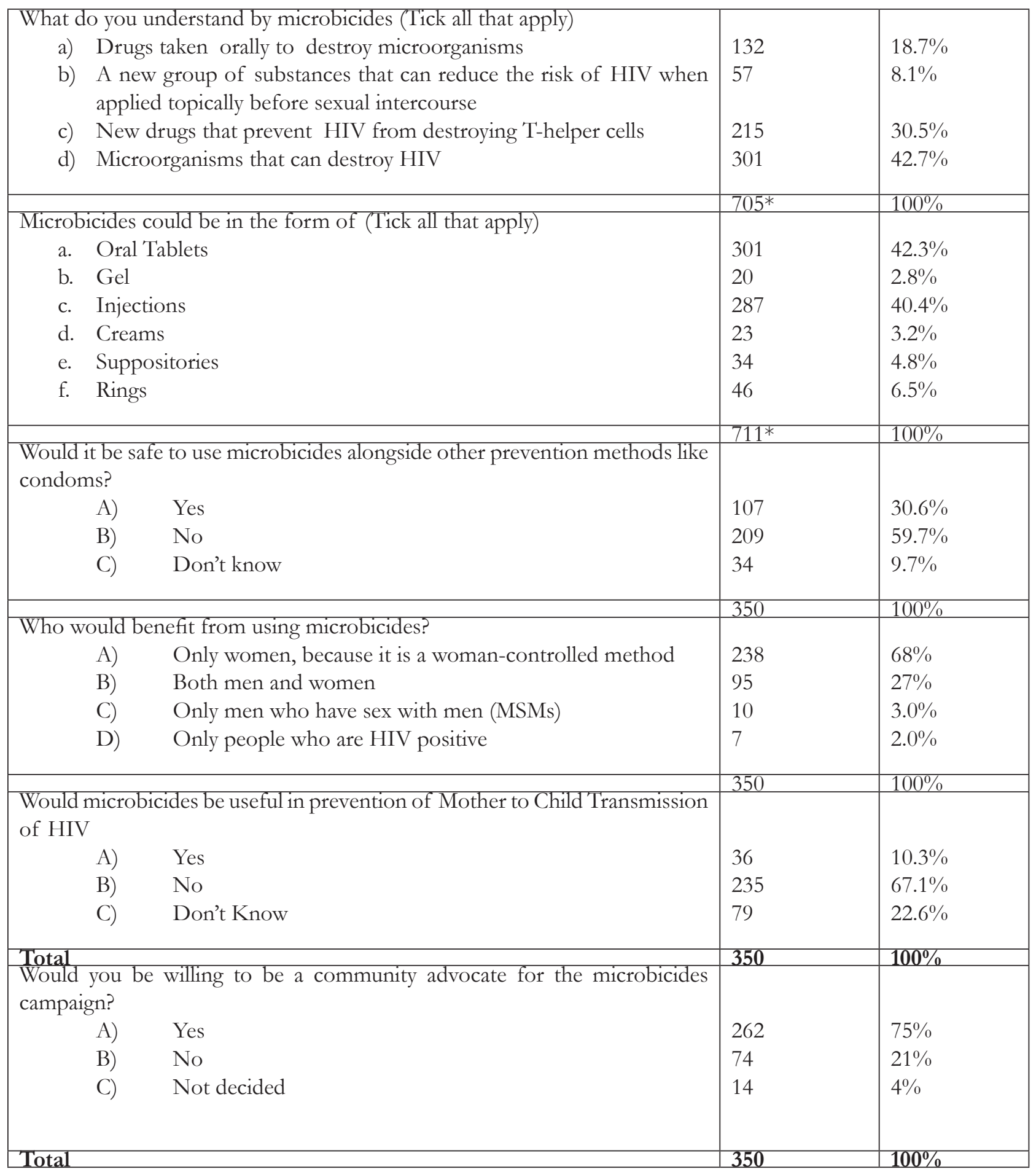

${ }^{*}$ Multiple responses allowed. 


\section{Discussion}

Most of the respondents, 200(57.1\%), were females. This may be explained by the high proportion of respondents who are nurses. In Nigeria, nursing is predominantly a female profession. Available data show that whereas only $20 \%$ of physicians and dentists across the country are women, $97 \%$ of nurses are women ${ }^{13}$. The high proportion of female participants may also explain why the majority of respondents, 238(68\%), indicated that only women would benefit from using microbicides since it is a woman-controlled method of HIV prevention. Interestingly, 235 (67.1\%) respondents indicated that micorbicides would not be useful in prevention of mother to child transmission of HIV. This finding may explain why the majority of respondents indicated that microbicides could not be used alongside other HIV prevention methods.

The number of responses to the question on sources of information regarding microbicides exceeds the total number of respondents. This indicates that some respondents had information about microbicides from more than one source. This is in contrast to the findings of Sow et al who found that most respondents in Dakar learnt about microbicides from only one source of information ${ }^{14}$. The low proportion of respondents who obtained information regarding microbicides from medical journals may be due to the high cost of printed copies of journals most of which are beyond the reach of most health care providers. The cost of accessing the internet in sub-Saharan Africa is still high anh hence, there is low internet uptake. Thus, most health care providers may not have access to online journals. More so, some online journals require financial subscription, which further puts them beyond the reach of health care providers in low income countries.

The paucity of research information on microbicides in local journals may further contribute to this low percentage. Only 9.\% of respondents obtained information concerning micrboicides from fellow health care providers. This could indicate that most health care providers do not know about microbicides so as to act as source of information to others. This indicates a knowledge gap that needs to be filled before the microbicides come on board as health care commodities.

Only $8.1 \%$ of health care providers had knowledge of what microbicides are compared to the $57 \%$ of hospital managers, $40 \%$ of pharmacists and $35 \%$ of nurses who had basic knowledge about microbicides as found by
Ramjee et al in a study among health care providers in South Africa ${ }^{10}$.

Majority of respondents indicated that it would not be safe to use microbicides alongside other prevention methods like condoms. This is another knowledge gap that has to be addressed. From the nature of the HIV/ AIDS pandemic, a multi-pronged prevention approach is necessary.

This study found that the majority of respondents had a favourable perception of microbicides as $75 \%$ of them would be willing to act as community advocates for the microbicides campaign. This is similar to the findings of Ramjee et all which found that almost $99 \%$ of health care providers indicated their colleague's willingness to recommend potential microbicides to clients if proven effective for HIV prevention ${ }^{7}$. This finding is a positive one and may indicate that health care providers would be willing to tell community members as well as their clients about microbicides. Such willingness is necessary to promote acceptance of healthcare commodity.

There was a statistically significant association between professional group and willingness to act as community advocates for microbicides. Medical doctors were more willing to act as advocates than other professional groups $\mathrm{p}=0.0001)$. There was also a statistically significant association between sex and correct knowledge of who would benefit from microbicides. Female respondents were more likely to have correct knowledge than males $(\mathrm{p}=0.0004)$. There was no statistically significant association between professional group and knowledge of the formulation of microbicides $(p=0.8000)$.

\section{Conclusion and recommendations}

The study has identified several gaps in knowledge regarding microbicides that can mar its uptake as a health care commodity. The high number of respondents willing to act as community advocates for the microbicides campaign offers ample opportunity for capacity building.

\section{References}

1. Divisions of HIV/AIDS Prevention . "HIV and Its Transmission". Centers for Disease Control \& Prevention, 2003. http://www.cdc.gov/HIV/pubs/ facts/transmission.htm. Retrieved 10th April,2012

2. UNAIDS. AIDS Epidemic Update. December 2007. Available at http://data.unaids.org/pub/ EPISlides/2007/2007_epiupdate_en.pdf. Retrieved $2^{\text {nd }}$ July, 2013. 
3. Uniting the World Against AIDS. http.//www.unaids.org. Retrieved April 10, 2009.

4. Federal Ministry of Health. HIV sentinel survey report,2001. FMOH, Abuja.

5. NACA . Global AIDS response progress report (GARPR) 2012. National Agency for the Control of AIDS, Abuja, Nigeria.

6. WHO/AFRO. HIV surveillance report for Africa 2000. Harare, Zimbabwe; 2001 November.

7.Global Campaign for Microbicides. About microbicides. http://www.global-campaign.org/about_ microbicides.htm. Retrieved January 23rd, 2012.

8. NHVMAS. Phase 2 trial of oral tenofovir use as A chemoprophylaxis for hiv infection In nigeria: the outcome of community Involvement with the scientific

Research process Report. Nigeria HIV Vaccine and Microbicicide Advocacy Group. http://www.nhvmasng.org/publication/tdf.pdf. Retrieved on July 13, 2013. 9. Microbicides. http://www.hivpreventionresearch. org/microbicides. Retrieved April 5, 2009.

10. Ramjee G, Morar NS, Mtimkulu J, Mantell JE, Gharbaharan V. Perceptions of vaginal microbicides as an HIV prevention method among health care providers in KwaZulu-Natal, South Africa. AIDS Res Ther. 2007; 4: 7.

11. Stover J. Understanding microbicide introduction in Africa and India. Paper presented at Toronto, August 13, 2006 http://ipm-microbicides.org/pdfs/english/ news_room/2006/john_stover.pdf. Retrieved April 1, 2009.

12. Mantell JE, Hoffman S, Exner TM, Morrissey KL, Lee JY, Brothers LP, Pili C. New York City health care providers' perceptions of female-initiated barrier methods: knowledge, acceptability and promotion. Int.Conf AIDS. 2002 Jul 7-12; 14: abstract no. MoPeF3859.

13. WHO. Human resource for health country profile Nigeria,http://www.hrhobservatory.afro.who.int/ images/Document_Centre/nigeria_country_profile. pdf. Retrieved 22nd November, 2012.

14. Sow PG, Ndiaye IP, Tal-Dia A, Diallo PD \& Traore I. Perceptions and practices regarding microbicides: a baseline survey of the Social Institute of Health and Hygiene of Dakar. International Research Journal of Microbiology (IRJM) (ISSN: 2141-5463) Vol. 3(1) pp. 039-044, January 2011 